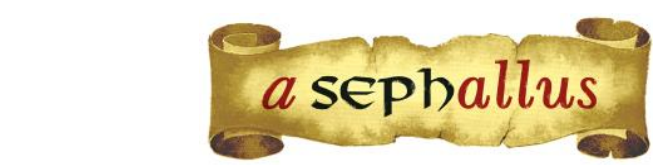

Revista aSEPHallus de Orientação Lacaniana

Núcleo Sephora de Pesquisa sobre o Moderno e o Contemporâneo

ISSN 1809 - 709 X

\title{
Uma reflexão sobre a transferência dos psicóticos na teoria freudiana ${ }^{1}$
}

\author{
Rafael Campos Dored \\ Orcid: https://orcid.org/0000-0002-9391-1940 \\ Mestre em psicologia clínica pela Universidade Federal do Paraná (Curitiba, Brasil) \\ Especialista em Psicologia Clínica: abordagem psicanalítica, pela PUCPR (Curitiba, Brasil) \\ E-mail: dored27@hotmail.com \\ Rosane Zétola Lustoza \\ Orcid: https://orcid.org/0000-0001-5299-4316 \\ Doutora em Teoria Psicanalítica pela Universidade Federal do Rio de Janeiro (RJ, Brasil) \\ Docente do PPG em psicologia pela Universidade Federal do Paraná (Curitiba, Brasil) \\ E-mail: rosanelustoza@yahoo.com.br
}

\begin{abstract}
Resumo: O artigo tem como objetivo identificar por que, de acordo com Freud, a transferência de pacientes psicóticos é inadequada para a clínica analítica. Descobrimos que essa afirmativa tem relação com o mecanismo de defesa empregado pelo psicótico que, diante de uma frustração, ao invés de recalcar, rechaça uma representação da consciência, e retorna a libido dessa representação de volta ao próprio ego, em pontos de fixação autoeróticos ou narcísicos. Depositada no Eu, a libido que se direciona para o mundo externo se tornou escassa, diminuindo a capacidade transferencial com o analista. Na esquizofrenia, Freud percebeu uma transferência insuficiente; na paranoia, de manejo impossível. Por conta disso, Freud não recomenda a psicanálise para tratar psicóticos, porque a análise se encerra precocemente, ou não apresenta ganhos terapêuticos. Não obstante, 0 autor deixa um grande alicerce teórico sobre as psicoses, e delega à posterioridade a responsabilidade de elaborar uma forma de tratamento.

Palavras-Chave: Psicanálise; Freud; Psicose; Esquizofrenia; Paranoia; Lacan.
\end{abstract}

Une réflexion sur le transfert chez les psychotiques dans la théorie freudienne : Cet article a le but $\mathrm{d}^{\prime}$ identifier la raison pour laquelle, selon Freud, le transfert des patients psychotiques est inapproprié pour la clinique analytique. Nous découvrons que cette affirmation est liée au mécanisme de défense employé par le psychotique qui, face à la frustration, au lieu de la réprimer, il rejette une représentation de la conscience et renvoie la libido de cette représentation au moi, aux points d'attachement auto-érotiques ou narcissiques. Déposée sur le Je, la libido dirigée vers le monde extérieur se raréfie, diminuant la capacité de transférer avec I'analyste. Dans la schizophrénie, Freud a remarqué un transfert insuffisant; dans la paranoïa, sa gestion est impossible. Par conséquent, Freud ne recommande pas la psychanalyse pour traiter les psychotiques, parce que l'analyse se termine trop tôt ou sans gains thérapeutiques. Cependant, l'auteur laisse une grande base théorique sur la psychose et il donne aux successeurs la responsabilité de développer une forme de traitement.

Mots-clés: Psychanalyse ; Freud; Psychose; Schizophrénie; Paranoïa; Lacan. 
A consideration about transference with psychotics in Freudian theory: The article aims to identify why, according to Freud, the transfer in psychotic patients is inappropriate for the analytical clinic. We found that this affirmation is related to the defense mechanism employed by the psychotic who, in the face of frustration, instead of repressing, rejects a representation in consciousness, and returns the libido of that representation back to the ego itself, in auto erotic or narcissistic fixation points. Deposited in the Self, the libido that is directed to the external world becomes scarce, decreasing the transference capacity with the analyst. In schizophrenia, Freud noticed an insufficient transfer; in paranoia, it is impossible to manage. Thus, Freud does not recommend psychoanalysis to treat psychotics, because the analysis ends early, or there are no therapeutic gains. Nevertheless, the author leaves a great theoretical foundation on psychoses, and delegates to his successors the responsibility of elaborating a form of treatment.

Keywords: Psychoanalysis; Freud, Psychosis; Schizophrenia; Paranoia; Lacan. 


\title{
Uma reflexão sobre a transferência dos psicóticos na teoria freudiana
}

\author{
Rafael Campos Dored \& Rosane Zétola Lustoza
}

\section{Introdução}

Os analistas praticantes não raro recebem pacientes psicóticos em seus consultórios. Por vezes, trata-se de uma psicose já evidentemente deflagrada, de tal modo que os signos clássicos associados a essa estrutura se apresentam desde o início. Em outros momentos, aquele que parecia neurótico inesperadamente sofre um desencadeamento psicótico. Também existem os casos de psicose ordinária, de difícil diagnóstico. Nesse encontro do psicótico com o analista, ocorrem belíssimos trabalhos com grandes resultados terapêuticos. São diversos os intérpretes e comentadores da obra freudiana que se dedicam a essa clínica (J. Lacan (1956/1998), K. Abraham (1908/1959), C. Soler (1997/2007), D. Leader (2013), entre outros), oferecendo-nos alternativas aos tratamentos medicamentosos e ressaltando a importância de dar a esses pacientes um lugar de sujeito, em vez de perpetuar sua condição alienada.

Curiosamente, apesar da grande contribuição que a psicanálise pode oferecer atualmente a pacientes psicóticos, o próprio Freud, ao longo da maior parte de sua obra, mostrou-se reticente com relação à eficácia da psicanálise para esses sujeitos. Apesar de todo o vai e vem da teoria freudiana, com suas retificações e avanços em suas formulações sobre a psicose, o trecho a seguir, extraído do Esboço de Psicanálise (Freud, 1938/1998), resume o que o autor pensou durante a maior parte de seus escritos sobre o tratamento analítico para psicóticos: pelo menos até aquele momento, o método teria se mostrado inapropriado para tratar de tais pacientes.

Se o ego do paciente vai ser um aliado útil em nosso trabalho comum, deve - por mais árdua que tenha sido a pressão das forças hostis - ter conservado uma certa coerência e algum fragmento de compreensão das exigências da realidade. Mas isto não é de se esperar do ego de um psicótico; ele não pode cumprir um pacto desse tipo; na verdade, mal poderá engajarse. Muito cedo ter-nos-á abandonado, bem como a ajuda que lhes oferecemos, e nos mandado juntar-nos às partes do mundo externo que não querem dizer mais nada para ele. Assim, descobrimos que temos de renunciar à ideia de experimentar nosso plano de cura com os psicóticos - renunciar a ele talvez para sempre ou talvez apenas por enquanto, até que tenhamos encontrado um outro plano que se Ihes adapte melhor (Freud, 1938/1998, p. 200).

Essa afirmação é sustentada por uma série de textos do autor, com destaque para o caso Schreber, quando Freud (1911/1996) começou a elaborar uma metapsicologia da psicose, centrando a 
dinâmica de funcionamento dessa estrutura na regressão libidinal ao narcisismo, fator esse que impossibilitaria a transferência.

De acordo com Hanna (2018), as poucas observações que Freud fez a respeito do tratamento das psicoses foram interpretadas por muitos analistas como uma impossibilidade de analisar esses pacientes, "porque dificilmente apresenta fenômenos de transferência, e, nos casos em que estes ocorrem, não são manobráveis pelo analista pelo viés da interpretação" (p. 28). Desta forma, afirmouse, por um lado, que a transferência poderia não existir; como consequência, a análise ficaria privada de seu pré-requisito essencial e o tratamento não poderia ser levado adiante. Tal condição será doravante nomeada neste trabalho como transferência insuficiente. Por outro lado, afirmou-se que, em algumas situações, a transferência na psicose poderia até existir, porém ela não poderia ser manejada, já que sua mera presença não seria suficiente para a consecução dos objetivos terapêuticos. Tal condição será nomeada, no contexto deste trabalho, como de transferência imanejável.

Não obstante, acreditamos que essa elaboração freudiana acerca das possibilidades transferenciais da psicose continua gerando um debate importante na comunidade analítica. Por essa razão, o presente artigo vai investigar os fundamentos teóricos que compõem o raciocínio de Freud sobre o assunto, realizando um esforço contínuo em delimitar quais características apontam para o tipo clínico da esquizofrenia, ou para uma paranoia. Sendo assim, acreditamos que este artigo pode trazer uma contribuição teórica importante, visto que muitas vezes a psicose é estudada de maneira generalizada, sem levar em conta seus diferentes tipos clínicos. Essa diferenciação se faz essencial para se pensar tanto em um diagnóstico diferencial, quanto em um possível manejo clínico, motivo pelo qual precisa ser estudada em seus pormenores.

A partir dessa preocupação inicial, buscou-se investigar duas questões: por que os fenômenos de transferência na psicose são insuficientes para levar adiante um tratamento analítico? E por que, quando surgem, não poderiam ser manejados pelo analista?

\section{Método}

Este trabalho tem como característica ser uma pesquisa teórica. A metodologia utilizada foi, portanto, um levantamento bibliográfico com exame crítico das obras de Freud e de alguns intérpretes que estudaram o tema proposto. O referencial de análise empregado foi a psicanálise de orientação freudiana. Uma vez que o objetivo do artigo é delimitar com precisão a visão freudiana acerca da transferência com psicóticos, na maior parte do trabalho recorremos diretamente aos escritos originais do autor, deixando aos intérpretes um papel complementar para esclarecimento de algumas questões específicas. Ademais, seguindo uma consideração lacaniana acerca dos estudos de Freud, decidimos 
repartir o campo das psicoses em dois grandes conjuntos: a esquizofrenia (cuja transferência foi considerada insuficiente para o trabalho analítico), e a paranoia (caracterizada por sua transferência imanejável).

\section{A psicose e seus tipos clínicos em Freud}

Sabemos que Freud iniciou suas investigações sobre o aparelho psíquico através dos estudos com as histéricas e criou um método para curar diversos sintomas neuróticos. Todavia, não raramente ele se deparava com pacientes psicóticos e, pelo menos até certo ponto de sua vida, não se furtava ao trabalho de atendê-los (Ver Rascunho H (Freud, 1895/1990) e Rascunho K(Freud, 1896/1990).

A psiquiatria da época criou diversos tipos clínicos para pensar os sintomas que surgiam em pacientes psicóticos: confusão alucinatória, demência precoce, parafrenia, esquizofrenia e paranoia. Imerso nesse vocabulário, Freud se valeu dessa vasta nomenclatura ao tratar do assunto; todavia, segundo Lacan (1956/1988), "Freud traça uma linha divisora de águas, se assim posso me exprimir, entre paranoia de um lado e, do outro, tudo o que gostaria, diz ele, que fosse chamado de parafrenia, e que corresponde exatamente ao campo das esquizofrenias" (p. 12). Ou seja, apesar de se servir do cabedal de saberes da psicopatologia de sua época, Freud faz também uma entrada original no campo, introduzindo uma bipartição dentro da grande categoria da psicose. Essa bipartição indicada por Lacan não foi conseguida graças a uma descrição mais pormenorizada dos fenômenos clínicos, mas sim pelos avanços da teoria freudiana, que o levaram a um aprofundamento gradual de sua compreensão sobre o Eu.

A quais princípios psicanalíticos corresponderia essa fórmula bipartite paranoia/esquizofrenia? Freud entende que a paranoia envolve uma regressão ao narcisismo, onde há uma gestalt corporal unificada, já a esquizofrenia envolveria uma regressão ao autoerotismo. Recorrendo às contribuições mais recentes de Alvarez (2008), pode-se tomar como critério diferencial o excesso ou carência da unidade representada pelo Eu. A paranoia teria como núcleo primordial uma excessiva consistência do Eu, que aparece sob a forma dos fenômenos de autorreferência mórbida, na qual o mundo emite sinais que se endereçam ao paciente. Desse modo, na paranoia temos um Eu demasiado sólido, que se torna o ponto final de um vetor que parte do mundo e que o visa diretamente. Tais fenômenos elementares podem servir posteriormente à elaboração de um delírio, que visa explicar por qual razão o Eu é alvo desses eventos que o assediam e o acossam. Já na esquizofrenia, ocorre justamente uma excessiva fragmentação do Eu, através de fenômenos que Alvarez denomina xenopáticos, na xenopatia, há a conviç̧ão de que uma força alheia ao Eu assume o controle sobre os seus pensamentos e o seu corpo.

Revista aSEPHallus de Orientação Lacaniana. Rio de Janeiro, 14(28), 33-52, mai. 2019 a out. 2019. 
Em relação à esquizofrenia, faz-se necessário um esclarecimento terminológico. Freud inicialmente não aderiu ao uso desse termo que fora cunhado por Bleuler, preferindo em seu lugar empregar parafrenia. Em alguns textos, como em Sobre o Narcisismo: Uma Introdução (Freud, 1914/1996), ele chega a fazer um uso ampliado de parafrenia como sinônimo da própria psicose, reservando a denominação de parafrenia propriamente dita ao que hoje entendemos como esquizofrenia. Porém, essa sugestão terminológica de Freud tornou-se obsoleta e o termo cunhado por Bleuler acabou se tornando dominante

Com o passar dos anos, Freud foi lapidando seu conhecimento acerca das psicoses: formulou alguns pontos muito importantes na tentativa de diferenciar a esquizofrenia da paranoia - no que diz respeito aos sintomas e à etiologia - e inclusive tentou curar alguns pacientes. Por outro lado, apesar de todo seu esforço teórico e clínico, na maior parte de sua obra ele se posicionou desfavoravelmente à utilização da psicanálise para o tratamento destas afecções, o que é muito bem ilustrado por um trecho de sua obra Sobre o Narcisismo: Uma Introdução (Freud, 1914/1996):

Esses doentes, que eu sugeri designar como parafrênicos, mostram duas características fundamentais: a megalomania e o abandono do interesse pelo mundo externo (pessoas e coisas). Devido a esta última mudança, eles se furtam à influência da psicanálise, não podendo ser curados por nossos esforços (Freud, 1914/1996, p.11).

Neste trecho, Freud está argumentando sobre a impossibilidade de influenciar pacientes psicóticos (lembremos que, no texto em questão, parafrenia está empregada no sentido ampliado, como sinônimo da própria psicose, conforme esclarecemos anteriormente) pelo método analítico. Esta hipótese pode ser encontrada em diferentes obras do autor, vide Esboço de Psicanálise (Freud, 1938/1998), Um Estudo Autobiográfico (Freud, 1925/1998), entre outros. Todavia, é raro Freud citar exemplos clínicos que justifiquem esta afirmativa, e a metapsicologia que se propõe a explicá-la também carece de sintetização. A resposta que encontramos para justificar essa impossibilidade de tratamento de pacientes psicóticos pela psicanálise gira em torno do mecanismo defensivo empregado por eles, e como isso afeta ou impede o processo transferencial.

\section{A defesa na psicose e sua consequência para a transferência}

Em As neuropsicoses de defesa (1894/1990), Freud já havia construído uma teoria bastante perspicaz sobre os mecanismos de defesa da histeria, da neurose obsessiva e da confusão alucinatória (que entraria no grupo da esquizofrenia). Ele explica que o surgimento do sintoma ocorre quando o paciente se confronta com uma frustração que lhe suscita um afeto muito aflitivo, sobre o qual se vê 
incapaz de chegar a uma solução; sendo assim, decide por esquecê-lo. Em algumas pessoas, esse esquecimento não vai trazer consequências, mas, em outros casos, pode acarretar reações patológicas histéricas, obsessivas ou psicóticas.

Freud descobriu que os mecanismos defensivos da neurose e psicose não são idênticos. Na neurose, o mecanismo defensivo (recalque) atua separando uma representação aflitiva de seu afeto correspondente, de forma que, sem libido, esta representação pode ficar desligada da cadeia associativa e, assim, tornar-se inconsciente. Na histeria, o afeto vai ser direcionado para vias somáticas; na neurose obsessiva vai achar uma representação substituta.

De maneira distinta, na psicose o Eu emprega "uma espécie de defesa muito mais poderosa e bem-sucedida" (Freud, 1894/1990, p.69) quando rejeita (Verwerfung) tanto a representação incompatível quanto seu afeto correspondente, e atua como se isso jamais tivesse ocorrido. Como resultado dessa rejeição, pode-se perceber dois desfechos distintos: na psicose alucinatória (esquizofrenia), uma parte do Eu vai ser parcialmente desligado do mundo externo e vai produzir alucinações para fortalecer a defesa; na paranoia, o sujeito projeta o conteúdo aflitivo para fora do ego, que retorna para si proveniente do exterior, sob forma de vozes, sentimentos persecutórios ou delírios.

Neste sentido, neurose e psicose possuem distintos mecanismos de defesa contra uma frustração, e ambas distanciam o sujeito da realidade exterior, como será explicado por Freud em $A$ perda da realidade na neurose e na psicose (1924/1998). A neurose é caracterizada por um conflito entre o Eu e o Isso, uma vez que o Eu se utiliza do recalque para desligar de seu afeto uma representação conflituosa. Já a psicose é resultado de um conflito entre o Eu e o mundo externo: por meio do mecanismo de defesa da rejeição, serão rejeitados da consciência tanto a representação da realidade quanto $o$ afeto correspondente.

Uma vez que o psicótico rejeita uma frustração, é criada uma fenda na relação do sujeito com seu mundo externo, quando ocorre um desligamento parcial do eu com a realidade que o cerca. Como resultado, será criado um novo mundo, delirante ou alucinatório, no qual aquela frustração não esteja presente. Sendo assim, o sintoma vai ser resultado de uma decisão do ego: no caso da neurose, permanecer fiel à realidade e tentar silenciar o Id, ou, no caso da psicose, ser derrotado pelo Id e, assim, arrancado de sua relação com a realidade (Freud, 1924/1998).

Por conseguinte, a diferença inicial assim se expressa no desfecho final: na neurose, o fragmento da realidade é evitado por uma espécie de fuga, ao passo que na psicose ele é remodelado . . . Ou ainda, expresso de outro modo: a neurose não repudia a realidade, 
apenas a ignora; a psicose a repudia (Verleugnung) e tenta substituí-la (Freud, 1924/1998, p. 231).

Sendo assim, neuróticos e psicóticos empregam mecanismos para não se haver com alguma representação insuportável. No entanto, o retorno disto que foi colocado de fora da consciência se dá de diferentes maneiras nesses dois grupos. Na neurose, isto que foi recalcado retorna como repetições, fobias, chistes. Retorna ali mesmo onde foi recalcado, no próprio discurso do paciente, mas desfigurado pelos mecanismos do recalque. Por outro lado, aquilo que foi rejeitado pelo mecanismo psicótico retorna para o sujeito no real e parece se originar de fora, de um outro, e com a peculiaridade de esconder sua autoria. Pode-se citar como exemplo as vozes e alucinações que invadem o psicótico: apesar de seu conteúdo ser composto por seus próprios pensamentos, o sujeito não os reconhece como seus, mas os situa como advindos de fora, de um outro que o invade sem sua permissão.

É por essa razão que Lacan (1955-1956/1996, p. 128) argumenta que, na neurose, o recalcado reaparece in loco, ou seja, ali mesmo onde foi recalcado, no meio dos símbolos, mas se utilizando de uma máscara; o homem se integra a esse recalcado participando como seu agente e autor. O retorno se dá pelo sintoma, pelo sonho, pelo ato falho, aqui tomados pelo sujeito como símbolos, ou seja, como representantes de uma mensagem latente. Já na psicose, isto que foi abolido reaparece em um outro lugar, in altero, mas dessa vez sem máscara. Retorna como se fosse parte da realidade, não como algo metaforizável.

Essa diferença entre recalque e rejeição se demonstra na obra de Freud em diferentes momentos, mas demanda atenção para captar suas nuances, porque para caracterizar o mecanismo de defesa psicótico, Freud utiliza palavras que variam conforme o momento de suas elaborações. Se por um lado o recalque da neurose foi facilmente identificado como Verdrängung, a rejeição passou por diferentes nomes: nos textos iniciais (1894-96/1990) e no caso do Homem dos lobos (1918/1996), o autor utiliza a palavra Verwerfung, no caso Schreber (1911/1996), Aufogehobene, e mais adiante, Verleugnung (1923-24/1998). De qualquer forma, independente da palavra utilizada, o conceito de rejeição se mantém praticamente inalterado ao longo de sua obra, e significa "um mecanismo de defesa muito mais poderoso e bem-sucedido, que em vez de reprimir a representação aflitiva, a cancela, ou abole para fora da consciência" (Freud 1911/1996, p. 61).

Mas por que motivo um sujeito vai se defender de uma frustração por intermédio da rejeição psicótica em vez do recalque neurótico? Freud vai explicar essa diferença por conta dos pontos de fixação que o sujeito construiu ao longo de seu desenvolvimento libidinal, uma articulação que ele já

Revista aSEPHallus de Orientação Lacaniana. Rio de Janeiro, 14(28), 33-52, mai. 2019 a out. 2019. 
expôs em Três ensaios sobre a teoria da sexualidade (Freud, 1905/1990), e que vai ser aplicado para explicar o caso do Presidente Schreber (Freud, 1911/1996).

Frente a uma frustração na realidade, a libido tende a tomar um rumo regressivo em busca de uma satisfação alternativa em organizações anteriores, ou em objetos abandonados pelo sujeito. Esta regressão caminha até os pontos de fixação que o sujeito formou ao longo de seu desenvolvimento. Os pontos de fixação, por sua vez, se formam quando uma pulsão não acompanha um desenvolvimento normal, que, inibido, permanece num estágio infantil. Essa pulsão, que não se desenvolveu adequadamente, vai se comportar no esquema libidinal como recalcada, ou seja, inconsciente. Quando o sujeito se confronta com uma frustração, a libido investida nessa situação traumática vai sofrer uma regressão até este ponto de fixação constituído pelo sujeito. $O$ fator de destaque neste raciocínio, é que diferentes pontos de fixação vão trazer diferentes sintomas, e as fases nas quais essa pulsão recalcada ficou fixada vão explicar a predisposição para doença futura (Freud, 1911/1996, p. 58).

Ainda sobre a articulação frustração-regressão-fixação, Freud argumenta que, quanto mais precoce forem os pontos de fixação libidinal no desenvolvimento do sujeito, mais grave será a manifestação patológica. Como exemplo, ele diferencia os pontos de fixação da paranoia e da esquizofrenia: na paranoia as fixações libidinais vão se dar em um período caracterizado pelo narcisismo, motivo pelo qual surgem sintomas de megalomania ou perseguição. Enquanto na esquizofrenia, a regressão se estende não simplesmente ao narcisismo [...] mas a um completo abandono do amor objetal e um retorno ao autoerotismo infantil. A fixação disposicional deve, portanto, achar-se situada mais atrás do que na paranoia e residir em algum lugar no início do curso do desenvolvimento entre o autoerotismo e o amor objetal (Freud, 1911/1996, p. 102).

É exatamente nesse ponto que reside a possibilidade ou impossibilidade de realizar transferência. Lembremos que, no caso das neuroses, a capacidade de transferência está preservada: isso ocorre porque, diante de uma frustração, a libido entraria em um curso regressivo até encontrar uma satisfação substitutiva em fantasia. Quando o sujeito retira libido de algum objeto do mundo exterior e a reinveste na fantasia, esse objeto fantasiado pode ser substituído - numa cadeia associativa - pela figura do analista, o que possibilita a transferência. Já no caso das psicoses - cujos pontos de fixação variam entre narcisismo e autoerotismo -, quando a libido é retirada do mundo exterior por conta de uma frustração, esta libido não será reinvestida em uma fantasia, em vez disso, vai retornar ao próprio corpo como objeto de investimento libidinal. A regressão pode se dar à imagem corporal de si (o ego narcísico) ou ao corpo fragmentado (autoerotismo). Quando o paciente tenta reinvestir essa libido em objetos da realidade, isto será realizado pelas vias projetivas ou alucinatórias, dificultando ou impossibilitando a transferência com o analista (Freud, 1914/1996, p.11).

Revista aSEPHallus de Orientação Lacaniana. Rio de Janeiro, 14(28), 33-52, mai. 2019 a out. 2019. 
Assumindo que a paranoia implica uma retração ao narcisismo e a esquizofrenia, ao autoerotismo, é de se esperar que as consequências de tal regressão não sejam as mesmas nos dois casos. Se tomarmos como parâmetro a relação do Eu com os objetos da realidade, o nível de regressão determina efeitos distintos, sobretudo no que diz respeito à relação com o analista. Na sequência, será feito um exame mais minucioso da transferência em cada tipo clínico.

\section{A esquizofrenia: uma transferência insuficiente}

O mecanismo regressivo de tomar o próprio corpo fragmentado como objeto de investimento libidinal é justamente a característica esquizofrênica que impossibilita a relação transferencial em análise. De acordo com Freud, como vimos acima, o ponto de fixação da esquizofrenia se instalou em uma fase autoerótica, com um completo abandono das relações objetais, e a consequência disto é que, diante de uma frustração, a tendência do esquizofrênico é retirar libido do mundo externo, que é insuportável para ele, e introjetar esta libido de volta ao próprio corpo.

Esse é um momento do processo esquizofrênico que corresponde aos fenômenos típicos desse quadro clínico, no qual o que entra em jogo é uma extrema dispersão, uma ameaça à unidade do Eu. $\mathrm{O}$ sujeito relata que tem seus pensamentos publicados, que tem a intimidade da sua mente vigiada; ou é então seu corpo que foge ao controle: seus órgãos lhe escapam, não obedecem à sua vontade, viram os órgãos de um estranho; ou ainda é seu discurso que o trai: este descarrilha, nada comunica, carece de um eixo. Exemplos de manifestações comuns na esquizofrenia, na qual o paciente tem a convicção de que seus pensamentos e seu corpo caíram sob o poder de uma força estranha e alheia a si próprio, razão pela qual Alvarez (2008) chama tais fenômenos de xenopáticos.

A questão é que isso gera um excesso de fragmentação que muitas vezes se torna, ela também, insuportável, traduzida por uma carência do Eu e por sua invasão nos fenômenos de automatismo. "É o fantasma de intrusão que, se na neurose histérica aparece como fantasma de violação, nas esquizofrenias aparece como fantasma de desgarramento e despedaçamento do corpo" (Godino Cabas, 1988, p. 121). Acrescentemos que isso que o autor chama de fantasma na esquizofrenia tem o estatuto de uma certeza, que deixa o paciente entregue à perplexidade.

O interessante é que tal fato pode levar o esquizofrênico a formular um pedido. "É por isto que o esquizofrênico pede sem limite nem cansaço; o que pede é que sua morte seja anulada. "Peço, logo existo", é a fórmula. E então, acontece que o esquizofrênico pede para nascer, pede para ser" ( $p$. 120). Esse pedido parece estar destinado ao fracasso, razão pela qual Godino marca a sua reiteração indefinida, ou ainda a tentativa de realizar uma passagem ao ato agressiva. Freud certamente não desconhecia essas possibilidades de um esquizofrênico dirigir-se a alguém; porém, tal fato não parecia ao autor ser suficiente para configurar a instância da transferência.

Revista aSEPHallus de Orientação Lacaniana. Rio de Janeiro, 14(28), 33-52, mai. 2019 a out. 2019. 
Sendo assim, é por conta dessa característica esquizofrênica, de regressão ao autoerotismo, que a transferência com pacientes esquizofrênicos graves se faz insuficiente para o trabalho analítico. Uma vez que a defesa esquizofrênica retirou libido demasiada do mundo externo e introjetou de volta no próprio corpo, a conexão do paciente com a realidade se tornou tão escassa que não mais é possível direcionar libido ao analista (Freud, 1925/1998). Dessa forma, os fenômenos transferenciais que surgiam com pacientes neuróticos não se apresentam na psicose da mesma maneira, o que torna o método freudiano, criado para tratar as neuroses, inapropriado para tratar os esquizofrênicos.

\section{A paranoia: uma transferência imanejável}

Respondemos à primeira pergunta proposta neste trabalho explicando sobre a impossibilidade da transferência com pacientes psicóticos, em especial, os parafrênicos, atualmente chamados de esquizofrênicos. Todavia, ainda não respondemos por que, quando a transferência se faz presente na psicose, Freud alega a impossibilidade de manejá-la. Em Um estudo autobiográfico (Freud, 1925/1998), o autor vai comentar sobre uma inclinação à transferência negativa em casos de paranoia: "Quando não existe nenhuma inclinação para uma transferência de emoção tal como esta, ou quando se torna completamente negativa, como acontece na demência precoce ou na paranoia, então também não há qualquer possibilidade de influenciar o paciente por meios psicológicos" (Freud, 1925/1998, p. 24).

A esse respeito, Maciel (2008) argumenta que Freud não postula a transferência como algo impossível na psicose, mas sim de outra ordem, diferente daquela que ocorre na neurose. Diante disto, se faz necessário explorar o conceito de transferência negativa, uma vez que Freud o utiliza para designar como a transferência pode se apresentar em casos de paranoia, e por que ela pode ser manejada na neurose, mas não na psicose. Além disso, é interessante notar a presença da palavra influência nesse trecho, visto que este mesmo termo também foi utilizado em 1914, como vimos mais acima, para designar a impossibilidade de influenciar o paciente por meios psicanalíticos em casos de parafrenia.

Tratando das neuroses, Freud classificou a transferência em positiva e negativa. A leitura standard da teoria freudiana da transferência atribuiria à positiva os sentimentos de afeto e carinho que incentivam o paciente em sua busca de cura, já a negativa se referiria às pulsões agressivas e seus derivados, que, quando direcionados para o analista, sabotam a associação livre. Contudo é possível uma outra versão, mais sutil, do que seria a transferência negativa na própria obra freudiana, já que o negativo pode ser entendido no sentido de uma resistência muito intensa à análise. Se assim for, tanto o ódio quanto o amor muito intensos poderiam constituir uma transferência negativa: o

Revista aSEPHallus de Orientação Lacaniana. Rio de Janeiro, 14(28), 33-52, mai. 2019 a out. 2019. 
conceito se aplicaria então, não tanto a uma característica dos afetos (amorosos ou hostis), mas ao fato de estes serem favoráveis ou não à análise.

No caso particular da psicose, particularmente no que concerne à paranoia, os textos freudianos costumam ressaltar que a transferência, quando existe, apresenta-se de forma negativa. Isso quer dizer que, mesmo que assuma uma feição amorosa (uma erotomania, por exemplo), a transferência impediria o tratamento analítico. Isso é patente sobretudo quando o paciente está em processo de construção de um delírio. É suficiente lembrar aqui a gramática do delírio construída por Freud (1911/1996) no caso Schreber: esse alguém que me persegue, me ama loucamente, arrebata de mim o objeto amado, é sempre uma alteridade com quem não é possível estabelecer uma aliança terapêutica.

Faz-se necessário aqui observar que, na psicose, a transferência negativa não se manifesta do mesmo modo que na neurose - a saber, sob a forma de resistência. Isso porque a resistência supõe a possibilidade de um trabalho de elaboração por parte do sujeito - e é precisamente essa elaboração, ou seja, a possibilidade de reconhecer que há em si uma evitação do saber, que está vedada ao psicótico. Por essa razão, Maleval (2003) prefere empregar o termo obstáculo para se referir aos percalços do tratamento com psicóticos, em detrimento do termo resistência, que ele reserva para as neuroses.

Para compreender um pouco mais sobre como se dá a transferência na paranoia, vamos tomar como exemplo o caso Schreber. Dr. Flechsig foi o médico de Schreber durante uma primeira doença com caráter hipocondríaco, ocasião na qual obteve um certo sucesso no tratamento. Essa cura temporária provocou forte afeição por parte do paciente e de sua esposa, que inclusive deixaram uma foto do médico estampada na casa como forma de gratidão e admiração. Freud argumenta que, nesse caso, houve transferência por parte do paciente, que se lembrou de seu irmão ou de seu pai ante a figura do médico. "A fantasia que despertou uma oposição tão violenta no paciente tinha assim suas raízes num anseio, intensificado até um tom erótico, pelo pai e pelo irmão. Este sentimento, na medida em que se referia ao irmão, passou por um processo de transferência para o médico, Flechsig" (Freud, 1911/1996, p. 70).

O problema veio anos mais tarde, na irrupção da segunda doença, quando Schreber foi acometido por um desejo de cunho homossexual. Impossibilitado de dar-lhe lugar em suas elaborações conscientes, rejeitou essa ideia e seu afeto correspondente para fora da consciência pelo mecanismo de defesa psicótico -, de forma que a ideia foi colocada para fora da cadeia associativa, enquanto a libido que acompanhava esta ideia foi depositada no ego, causando uma série de consequências.

Revista aSEPHallus de Orientação Lacaniana. Rio de Janeiro, 14(28), 33-52, mai. 2019 a out. 2019. 
Como vimos anteriormente, o psicótico se desliga parcialmente do mundo externo quando dele retira sua libido e a reinveste no próprio ego. No caso das esquizofrenias, a tentativa de cura é criar alucinações para comprazer a defesa do ego, remodelando assim a realidade externa. Todavia, na paranoia a tentativa de cura se dá de uma outra maneira, que Freud nomeou de projeção:

O que se faz notar flagrantemente, para nós, é o processo de cura, que desfaz a repressão e reconduz a libido às pessoas por ela abandonadas. Ele se realiza, na paranoia, pela via da projeção. Não foi correto dizer que a sensação interiormente suprimida é projetada para fora; vemos, isto sim, que aquilo interiormente cancelado retorna a partir de fora (Freud, 1911/1996, p. 62).

Sendo assim, por conta de seu mecanismo de defesa psicótico, Schreber rejeitou seus desejos homossexuais para fora da consciência, que em seguida retornaram para si no real, por projeção. Esse retorno projetivo tem como característica um ocultamento de sua autoria, ou seja, o sujeito não percebe este sentimento rejeitado como proveniente de si mesmo, mas sim de um outro, in altero, como sugeriu Lacan. Portanto, a projeção psicótica não se reduz a atribuir ao mundo externo aquilo que teve origem internamente; afirmar isso seria pouco. Na projeção psicótica, a origem interna de uma ideia é cancelada, o que torna a possibilidade de seu reconhecimento posterior pelo Eu perdida. Por isso, quando ela retornar a partir de fora, será sob a forma de sua atribuição a uma origem externa.

Diante disso, podemos observar duas consequências. A primeira é que a ideia homossexual que foi rejeitada e retornou por projeção, desprovida de sua autoria (pois não sou eu que o ama, é ele que me ama), provocou todo o desencadeamento de um delírio de perseguição. Isto que jamais esteve presente na cadeia associativa do paciente retornou como algo indizível, sem sentido, impossível de se colocar em palavras, assumindo a forma de um malfeitor principal que se materializa na figura de Flechsig sob a forma de uma transferência delirante (Little, 1986). A segunda consequência tem relação com a libido rejeitada que, em vez de ser reinvestida na fantasia, foi depositada no Eu do paciente, que se torna o alvo dessa perseguição.

O que não ficou claro é por que um sentimento amoroso e erótico acabou se transformando em um sentimento persecutório e aterrorizante. É interessante notar a argumentação de Freud para explicar este ponto. Ele acreditava que a paranoia tinha sua origem em um desejo homossexual rejeitado, que retornará sob a forma da projeção. Todavia, nesse retorno projetivo, o conteúdo rejeitado sofrerá uma alteração quanto a sua autoria (em que o eu é substituído pelo outro), que pode se amplificar e atingir também sua relação ao conteúdo (em que o amor é substituído pelo ódio).

Revista aSEPHallus de Orientação Lacaniana. Rio de Janeiro, 14(28), 33-52, mai. 2019 a out. 2019. 
Uma vez que esse desejo homossexual surgiu em Schreber e não pôde ser aceito pela consciência, ele foi rejeitado, mas retornou na realidade por projeção, sendo o médico Flechsig o alvo desses sentimentos. Neste sentido, colocando Schreber e Flechsig na proposição freudiana temos: eu (Schreber) o amo (Flechsig) - em um deslocamento de um impulso que, em outro momento, teve como alvo o pai ou o irmão. Este sentimento é rejeitado da consciência e retorna por projeção com seu conteúdo e autoria deformados da seguinte forma: ele me odeia (Flechsig), e por isso me persegue. Esta ideia persecutória, além de mascarar a autoria dos desejos homossexuais do paciente, também se tornam um poderoso alicerce para as elaborações delirantes que Schreber vai formular ao longo de sua doença (Freud, 1911/1996).

Sendo assim, uma vez que o médico é colocado na figura de um perseguidor, qualquer tentativa de influência pela psicanálise se torna impossível. O mais provável é que o analista se torne ameaçador, fazendo com que o paciente abandone a análise, ou resultando em um trabalho sem ganhos terapêuticos (Freud, 1938/1998).

Neste ponto, surge um interesse em tentar diferenciar definitivamente a transferência de acordo com seu tipo clínico, ou seja, uma transferência paranoica e outra esquizofrênica. Todavia, no caso Schreber (1911/1996) Freud já nos adverte dessa impossibilidade, visto que Schreber, assim como inúmeros outros pacientes psicóticos, apresentou sintomas de ambos os tipos clínicos - paranoia e esquizofrenia -, assim como apresentou variações entre uma transferência insuficiente, alheio ao mundo externo, e outra intensamente negativa. O quadro clínico da psicose comporta uma oscilação entre os polos esquizofrênico e paranoico (Alvarez, 2008). O melhor que podemos fazer é definir os pontos de fixação que levam a sintomas paranoicos ou esquizofrênicos, e relacionar isto com suas possibilidades transferenciais, mas sempre lembrando que os pontos de fixação são vários, e essa regressão libidinal pode variar entre autoerotismo e narcisismo no mesmo sujeito.

Além disso, diante destas características transferenciais da psicose - na esquizofrenia uma transferência insuficiente, na paranoia uma transferência delirante (persecutória, erótica, etc.) -, Freud constatou que o principal mecanismo em sua técnica analítica para lograr êxito sob as resistências, a interpretação, não obtinha os mesmos resultados com esses pacientes, seja pela imobilidade e rigidez do delírio, quanto pela indiferença com que estes pacientes tratavam o médico.

Existem, entretanto, outras formas de doença nas quais, malgrado as condições sejam as mesmas, nossa conduta terapêutica jamais obtém êxito. Nelas também tem-se verificado que houve um conflito básico entre o ego e a libido, que acarretou a repressão - embora esse fato possa necessitar de uma descrição topográfica diferente; nelas, ademais, é possível determinar os pontos de vista do paciente, nos quais ocorreram as repressões; utilizamos o

Revista aSEPHallus de Orientação Lacaniana. Rio de Janeiro, 14(28), 33-52, mai. 2019 a out. 2019. 
mesmo procedimento, estamos prontos a fazer as mesmas promessas e oferecer a mesma ajuda apresentando ideias orientadoras; e, também nesse ponto, o tempo transcorrido entre as repressões e a época presente favorece um resultado diferente para o conflito. Ainda assim, não conseguimos remover uma única resistência ou suprimir uma única repressão. Esses pacientes, paranoicos, melancólicos, sofredores de demência precoce, permanecem, de um modo geral, intocados e impenetráveis ao tratamento psicanalítico (Freud, 1917/1996, p. 511).

Sendo assim, apesar dos esforços terapêuticos empreendidos, Freud concluiu que os pacientes psicóticos não são influenciáveis pelo analista, seja por conta de uma transferência que não se formou, ou pela prevalência de sua porção negativa, como em Schreber. Ademais, a revivescência do conflito patogênico e a superação das resistências, objetivos da análise com neuróticos, não produz os mesmos efeitos com psicóticos, o que levou Freud a argumentar que seu método analítico (criado para tratar as neuroses) não seria adequado para tratar as psicoses.

\section{Discussão}

Ao longo do trabalho, vimos que Freud considerou que a transferência de pacientes psicóticos ou é insuficiente para o trabalho analítico (na esquizofrenia), ou é impossível de ser manejada (na paranoia). Essas características transferenciais ocorrem devido aos pontos de fixação libidinal que esses pacientes formaram ao longo do seu desenvolvimento. Freud argumenta que diferentes pontos de fixação vão resultar em diferentes sintomas, assunto que abordamos minuciosamente ao longo do artigo, numa tentativa de delimitar o que está no campo de cada tipo clínico distintamente.

Esta retroversão da libido, que abandona os objetos do mundo externo e se volta para os pontos de fixação libidinal formados, ocorre quando o sujeito se depara com alguma representação inaceitável. Enquanto na neurose a libido desligada pelos mecanismos defensivos vai ser investida na fantasia, o psicótico tem a característica de investi-la no próprio corpo, agora tomado como objeto. 0 corpo aqui pode ser entendido em dois sentidos distintos: quando o corpo se refere à anarquia pulsional sem referência ao Eu narcísico, a fixação no autoerotismo resultaria na esquizofrenia; quando nos referimos à imagem totalizada de si, estamos no registro do Eu narcísico, a fixação resultaria na paranoia.

Disso, resultam momentos diferentes na relação do psicótico com a realidade. $\mathrm{Na}$ esquizofrenia a alteridade costuma não entrar, ou entrar de forma precária. A defesa efetuada pelo esquizofrênico é rejeitar uma porção da realidade (insuportável para ele) para fora da consciência, de maneira que isto não mais faça parte de suas associações e representações. Todavia, como vimos 
anteriormente, isto que foi rejeitado da consciência tende a retornar para o sujeito a partir do real. No caso da esquizofrenia, isto retorna de maneira invasiva, muitas vezes como distorções corporais, ou como uma sensação de intrusão no corpo, ou dominação dos pensamentos. As alucinações surgem, segundo Freud, como um remendo no lugar daquilo que foi rejeitado, como uma tentativa de cura: de retomar o sentido perdido pela exclusão de uma porção da realidade, além de dar sentido para isto que retorna de fora, no real, que surge como um enigma para o sujeito.

Com relação às consequências para a análise, esse mecanismo defensivo do esquizofrênico impede ou diminui a capacidade transferencial, nos levando ao termo utilizado no trabalho "transferência insuficiente". A retroversão da libido atinge uma dimensão tal que a conexão do paciente com a realidade se torna muito restrita, não sendo mais possível direcionar qualquer tipo de afeto para o analista. Neste caso, de ausência ou insuficiência da transferência, não é possível influenciar o paciente através da análise, o que a tornaria, na visão de Freud, ineficaz.

Se tratando da paranoia, pudemos observar que o mecanismo de defesa também é a rejeição de uma representação insuportável para o sujeito. Todavia, por conta da distinção entre os pontos de fixação libidinal (neste caso em uma fase narcísica), as consequências desta rejeição serão diferentes da esquizofrenia. Em vez que retornarem como invasões no corpo ou no pensamento, esse fragmento de realidade, rejeitado pelo sujeito, vai retornar como uma ameaça vindo de um outro, seja uma instituição, um vizinho, ou até mesmo algum desconhecido. Além disso, o ego não vai criar alucinações para explicar o vazio de sentido, mas formações delirantes, que se propõem a explicar os motivos pelos quais está sendo perseguido, vigiado, etc.

$\mathrm{Na}$ paranoia, a alteridade entraria como ponto de origem de um vetor que se dirige ao $\mathrm{Eu}$, razão pela qual essa alteridade será tomada na convicção delirante de ser perseguido por ela, ou ainda amado, roubado, etc. A transferência aqui está presente, mas não pode ser manejada, pois não há um fora desse círculo de certezas que compõem o delírio. Neste caso, quaisquer tentativas de interpretação se tornam inócuas, tanto por conta da rigidez característica do delírio, quanto pela prevalência da transferência negativa, que coloca o analista no lugar de perseguidor. Sendo assim, Freud argumenta que a análise com paranoicos ou se precipita a um fim precoce, ou não apresenta ganhos terapêuticos.

Apesar dessa correlação direta entre a retroversão da libido até os pontos de fixação libidinal e os tipos clínicos da psicose, um sujeito pode formar vários pontos de fixação ao longo do seu desenvolvimento. Isto resulta no fato de que um mesmo paciente pode apresentar sintomas de ambos os tipos clínicos no decorrer de seu tratamento, o que, consequentemente, também vai apresentar diferentes formas de transferência.

Revista aSEPHallus de Orientação Lacaniana. Rio de Janeiro, 14(28), 33-52, mai. 2019 a out. 2019. 
Sendo assim, uma vez que o tratamento analítico repousa no manejo transferencial que possibilita a superação das resistências para rememoração e elaboração do conteúdo inconsciente, concluímos que Freud considerou sua técnica analítica inadequada para tratar de pacientes psicóticos, pois a transferência com estes pacientes era imprópria para o trabalho terapêutico: ou porque não se concretizava, ou pela impossibilidade de manejá-la.

\section{Considerações Finais}

A partir de nossa pesquisa e análise crítica, pudemos demonstrar diferenças clínicas e metapsicológicas entre as formas transferenciais apresentadas pela esquizofrenia e pela paranoia. Ao longo do estudo encontramos diferentes momentos da teoria freudiana, de forma que apreender a lógica proposta pelo autor, e definir, com precisão, os conceitos utilizados para explicar o mecanismo defensivo da psicose, foi um desafio. Em alguns momentos o autor trata a psicose como um todo; em outros momentos ele distingue os tipos clínicos, se utilizando das diferentes nomenclaturas psiquiátricas da época; outra dificuldade foi delimitar as diferentes palavras que ele utiliza para denominar o mecanismo de defesa psicótico, o que decidimos nomear de rejeição. Por fim, com relação à transferência na psicose, os fragmentos que tratam do assunto estavam espalhados em diferentes textos e, na maioria das vezes, Freud tratou o assunto de forma abrangente.

Por isso, acreditamos que este artigo tem uma valiosa contribuição teórica sobre a transferência na psicose, porque conseguiu sintetizar e organizar uma construção lógica de difícil compreensão, que foi se modificando e se consolidando ao longo dos anos na obra freudiana. Ademais, essa precisão teórica além de colaborar para o esclarecimento lógico do assunto, também tem uma utilidade prática quanto a realização de diagnósticos diferenciais. Uma vez que esquizofrenia e paranoia se diferenciam quanto aos seus pontos de fixação libidinal e às tentativas de cura, se torna possível pensar diante de qual tipo clínico nos encontramos, e quais suas possibilidades de transferência.

Sendo assim, apesar de não ter elaborado um manejo possível para a clínica com as psicoses, Freud construiu um alicerce teórico fundamental para a abordagem destas, inclusive delegando à posteridade a responsabilidade de elaborar uma forma de tratamento. Reforçamos esta ideia comentando sobre a revolução clínica que Freud realizou na época, quando considerou o delírio como uma tentativa de cura efetuada pelo paciente, fenômeno que era visto, na psiquiatria, como o principal representante da doença. Além disso, em Análise terminável interminável, o autor teve um lampejo que decididamente influenciou psicanalistas que vieram posteriormente: "Assim renunciaríamos ao empenho vão de convencer o doente do desvario de seu delírio, sua contradição com a realidade

Revista aSEPHallus de Orientação Lacaniana. Rio de Janeiro, 14(28), 33-52, mai. 2019 a out. 2019. 
objetiva, e em troca encontraríamos no reconhecimento desse núcleo de verdade um solo comum sobre o qual pode se desenvolver o trabalho terapêutico" (Freud, 1937/1998, p. 156).

A teoria freudiana possibilitou aos futuros psicanalistas a criação de novas alternativas para essa clínica. Atualmente, temos diversos trabalhos psicanalíticos que discorrem sobre variadas formas de manejar a transferência psicótica, e de que forma a psicanálise pode contribuir para a estabilização desses pacientes. No cenário atual, a possibilidade de transferência do psicótico continua sendo fonte de diversos debates. Por outro lado, a clínica com esses pacientes vem ganhando muito espaço dentro e fora das instituições, auxiliando na estabilização de casos graves e em sua inserção social. De qualquer forma, esta é uma discussão que iremos abordar em artigos subsequentes.

Somente com o intuito de exemplificação podemos citar Lacan, que seguiu a elaboração freudiana de renunciar ao empenho vão de convencer o doente do desvario de seu delírio. A partir deste raciocínio, o autor propôs a clínica do secretário do alienado (Lacan, 1955-56/1988), que em vez de tentar decifrar o inconsciente do psicótico através da interpretação, se coloca como um destinatário desse discurso delirante, apostando que, a partir dessa construção, o paciente possa formular alguma solução que possibilite estabilizar-se. Afinal de contas, se o delírio é a tentativa de cura empregada pelo psicótico, faz mais sentido ouvi-lo que refutá-lo.

\section{Notas:}

1. Artigo escrito no âmbito da universidade Federal do Paraná, e subsidiado por uma bolsa de estudos oferecida pela CAPES. Atividades desempenhadas no artigo: pesquisa e escrita a cargo de Rafael Campos Dored; orientação, escrita e revisão final a cargo de Rosane Zétola Lustoza.

\section{Referências Bibliográficas}

Abraham, K. (1908) Las diferencias psicosexuales entre la histeria y la demencia precoz. In Psicoanálisis clínico. Buenos Aires: Paidós, 1959.

Alvarez, J. Estudios sobre la psicosis. Buenos Aires: Grama, 2008.

Clérembault, G (1995) Automatismo Mental: Paranoia. Bueno Aires: Polemos.

Freud, S. (1894) As neuropsicoses de defesa. In Edição standard das obras completas de Sigmund Freud v. III (pp. 13-37). Rio de Janeiro: Imago, 1990.

Freud, S. (1895) Rascunho H. In Edição standard das obras completas de Sigmund Freud v. I (pp. 123-127). Rio de Janeiro: Imago, 1990. 
Freud, S. (1896) Rascunho K. In Edição standard das obras completas de Sigmund Freud v.I (pp. 131149). Rio de Janeiro: Imago, 1990.

Freud, S. (1905) Três ensaios sobre a teoria da sexualidade. In Edição standard das obras completas de Sigmund Freud v. VII (pp. 117- 229). Rio de Janeiro: Imago, 1990.

Freud, S. (1911) Notas psicanalíticas sobre um relato autobiográfico de um caso de paranoia. In Edição standard das obras completas de Sigmund Freud v. XII (pp. 5-49). Rio de Janeiro: Imago, 1996.

Freud, S. (1914) Sobre o Narcisismo: Uma Introdução. In Edição standard das obras completas de Sigmund Freud, v. XIV (pp. 43-63). Rio de Janeiro: Imago, 1996.

Freud, S. (1915) Observações Sobre o Amor Transferencial. In Edição standard das obras completas de Sigmund Freud, v. XII (pp. 97-106). Rio de Janeiro: Imago, 1996.

Freud, S. (1917) Conferência XXVII - Transferência. In Edição standard brasileira das obras completas de Sigmund Freud v. XVI (pp. 503-521). Rio de Janeiro: Imago, 1976.

Freud, S. (1925) Um Estudo Autobiográfico. In Edição standard das obras completas de Sigmund Freud v. XX (pp. 2-46). Rio de Janeiro: Imago, 1998.

Freud, S. (1937) Análise terminável e interminável. In Edição standard das obras completas de Sigmund Freud v. XXIII (pp. 223-270). Rio de Janeiro: Imago, 1998.

Freud, S. (1940/1938) Esboço de psicanálise. In Edição standard das obras completas de Sigmund Freud v. XXIII (pp. 151-222). Rio de Janeiro: Imago, 1998.

Godino Cabas, A. (1988). A função do falo na loucura. Campinas: Papirus.

Hanna. M. (2018). A transferência no campo da psicose: uma questão. Rio de Janeiro: Subversos.

Lacan, J. (1988). Seminário livro 3, as psicoses, 1955-56 (A. Menezes, trad.) Rio de Janeiro: Zahar. (trabalho original publicado em 1981)

Lacan, J. (2007). Seminário livro 23, o sinthoma, 1975-76 (Laia. S, trad.) Rio de Janeiro: Zahar. (Trabalho original publicado em 2005)

Little, Margaret (1986). Transference neuroses and transference psycosis. England: Free Association Book.

Maciel, V.A. (2008, junho) A transferência no tratamento da psicose. Mental, 10 (6), 31-40.

Maleval, J.-C. (2003) La forclusion del nombre del padre: el concepto y su clinica. Espanha. Paidos Iberica.

Soler, C. (1997). Autismo e paranoia. In. O inconsciente a céu aberto da psicose. Rio de Janeiro: Zahar, 2007, pp. 63-80.

Revista aSEPHallus de Orientação Lacaniana. Rio de Janeiro, 14(28), 33-52, mai. 2019 a out. 2019. 
Citação/Citation: Campos Dored, R. \& Zétula Lustoza, R. (mai. 2019 a out. 2019). Uma reflexão sobre a transferência dos psicóticos na teoria freudiana. Revista aSEPHallus de Orientação Lacaniana, 14(28), 33-52. Disponível em www.isepol.com/asephallus. Doi: 10.17852/1809-709x.2019v14n28p33-52

Editor do artigo: Tania Coelho dos Santos.

Recebido/Received: 02/08/2019 / 08/02/2019.

Aceito/Accepted: 04/10/2019 / 10/04/2019.

Copyright: (c) 2019 Associação Núcleo Sephora de Pesquisa sobre o moderno e o contemporâneo. Este é um artigo de livre acesso, que permite uso irrestrito, distribuição e reprodução em qualquer meio, desde que o autor e a fonte sejam citados/This is an open-access article, which permites unrestricted use, distribution, and reproduction in any medium, provided the author and source are credited. 